\title{
Minúsculos terroristas
}

\author{
Little terrorists
}

Miúdos terroristas

\section{Debra A. Castillo}

CORNELL UNIVERSITY, ESTADOS UNIDOS

Stephen H. Weiss Presidential Fellow, Emerson Hinchliff Chair of Hispanic

Studies, y Professor of Comparative Literature en Cornell University.

Es autora de Re-dreaming America: Toward a Bilingual American

Culture (SUNY, 2004), Border Women: Writing from La Frontera

(con M. S. Tabuenca Córdoba, Minnesota UP, 2002), Easy Women:

Sex and Gender in Modern Mexican Fiction (Minnesota UP, 1998), y

Talking Back: Toward a Latin American Feminist Literary Criticism

(Cornell UP, 1992), entre otros. Es, también, coeditora de múltiples volúmenes, entre los que se cuentan Theorizing Fieldwork in the

Humanities (con Shalini Puri, Palgrave MacMillan, 2016), y Despite

all Adversities: Spanish-American Queer Cinema (con Andrés Lema-

Hincapié, SUNY, 2015). Correo electrónico: dac9@cornell.edu

Artículo de reflexión.

Documento accesible en línea desde la siguiente dirección: http://revistas.javeriana.edu.co

doi:10.11144/Javeriana.cl21-42.mite 


\section{Resumen}

De manera comparada y transmedial, este trabajo pone en escena una serie de materiales que hacen entrar en crisis las concepciones comunes, en Occidente, sobre la niñez, en especial la masculina; a saber, el filme Little Terrorist, una fotografía de Diane Arbus y las novelas El ejército iluminado de David Toscana y Loosing my Espanish de H.G. Carrillo. A partir de estos materiales, el trabajo discute la manera en que la cultura hegemónica sostiene una ley de valores que, amparada en la díada niñez-inocencia, naturalizan la violencia.

Palabras clave: infancia-aspectos culturales; pedagogía de género; violencia; H.G Carrillo; David Toscana

\section{Abstract}

In a comparative and transmedial way, this work presents a series of materials that bring a crisis to common Western conceptions about childhood, especially the masculine one. Namely, the film Little Terrorist, a photograph by Diane Arbus, and the novels The Illuminated Army by David Toscana and Loosing my Espanish by H.G. Carrillo. Based on these materials, this work discusses the way in which hegemonic culture maintains a law of morals that, under the protection of the childhoodinnocence duo, naturalizes violence.

\section{Keywords: childhood-cultural} aspects; gender pedagogy; violence; H.G Carrillo; David Toscana

\section{Resumo}

De maneira comparada e transmedial, este trabalho põe em cena uma série de materiais que fazem entrar em crise as concepções comuns, em Ocidente, sobre a meninice, em especial a masculina; a saber, o filme Little Terrorist, uma fotografia de Diane Arbus e os romances El ejército iluminado de David Toscana e Loosing my Espanish de H.G. Carrillo. A partir destes materiais, o trabalho discute a maneira em que a cultura hegemônica sustem uma lei de valores que, amparada na díade meninice-inocência, naturalizam a violência.

Palavras-chave: infância-aspetos culturais; pedagogia de gênero; violência; H.G Carrillo; David Toscana

RECIBIDO: 15 DE JULIO DE 2016. ACEPTADO: 29 DE NOVIEMBRE DE 2016. DISPONIBLE EN LÍNEA: 29 DE DICIEMBRE DE 2017

\section{Cómo citar este artículo:}

Castillo, Debra A. "Minúsculos terroristas". Cuadernos de Literatura 21.42

(2017): 238-253. https://doi.org/10.11144/Javeriana.cl21-42.mite 
Comencé a DARLE vueltas al tema de este ensayo a través de la conjunción de una serie de textos escritos y visuales producidos tanto en Estados Unidos como en la frontera sur de Asia: Pequeños terroristas, el corto de Ashvin Kumar nominado al Óscar en el año 2005 (figura 1); la obsesionante fotografía de Diane Arbus, "Niño con granada de juguete en Central Park" (1962) (figura 2); así como las imágenes de niños soldados y sicarios contemporáneos que permean las noticias y los websites de las organizaciones no gubernamentales (figura 3). Estas son imágenes que me obsesionan conforme leo textos literarios como El ejército iluminado del novelista mexicano David Toscana o Loosing my Espanish del cubano-americano H.G. Carrillo. ${ }^{1} \mathrm{Al}$ asociarse con niños, cada uno de estos textos e imágenes aumenta - y luego difumina- el espectro de la violencia, pero lo hace de una forma muy particular. Cada uno presume un arraigo necesario en una historia violenta que debe ser repudiada y de la cual los niños deben ser protegidos. Al mismo tiempo, los niños están comprometidos con aprender esta historia y con representarla e interiorizarla en el carácter físico corriente de sus cuerpos infantiles. A cada uno de estos textos, entonces, podríamos enfrentarlo a la pregunta perceptiva de Kathryn Bond Stockton: "But, how does innocence, our deffault designation for children, couse its own violence?" (5).

En las fotografías señaladas, por ejemplo, cada uno de los niños está agarrando un juguete $-o$, en el caso de la fotografía sudanesa, un arma real- que de inmediato, si bien ominosamente, se desfamiliariza en la incongruencia que provoca el contraste entre la vulnerabilidad de la expresión corporal del niño y la particularidad histórico-geográfica que el adulto utiliza como contexto para comprender dicha imagen. Esta asociación de los niños presuntamente inocentes con armas/juguetes es en cada una de estas imágenes impropia, absurda, increíble; la presunción de inocencia juvenil que el

1 También tengo muy presente la adaptación de Elaine Romero de La journée de la jupe en abril del 2013 para el programa teatral del Teatrotaller/Cornell. "Mother of Exiles" es una obra que toma lugar en una clase problemática en un pueblo pequeño de los Estados Unidos parcialmente poblado por inmigrantes latinos. Los estudiantes son irrespetuosos y revoltosos hasta que una pistola cae de la mochila de alguien. La acosada profesora recoge el arma, y transforma su clase, dándole un giro; se hace cargo por medio de la amenaza de violencia, y demanda que los estudiantes se aprendan su lección de teatro. Con el tiempo, los estudiantes aprenden nuevas perspectivas acerca de la obra que están estudiando y sobre sí mismos, reconociendo cómo tomar responsabilidad por su educación y acción en sus comunidades. La audiencia aprende por qué estos estudiantes son tan infelices en su ambiente, y todos descubrimos al final de la clase que la profesora también es latina pero ha estado escondiendo su identidad. 
espectador trae consigo define de modo fundamental el sentido de las imágenes como potente y extraño. $\mathrm{Y}$, sin embargo, al mismo tiempo, el miedo de/a los niños (en ambos sentidos), y especialmente la naturalidad socialmente condicionada del vínculo entre niños y armas, parece complemente apropiada para sociedades que oscilan entre identificar a los niños con un estado inexplorado de inocencia y, al mismo tiempo, los alientan, especialmente a los hombres, a jugar a la violencia con armas reales y de juguete. Este es un tropo bastante común para aquellos que disfrutan con entretenciones que refuerzan nuestra recurrente fascinación con las juventudes asesinas (prominentes ejemplos en lengua inglesa podrían incluir El señor de las moscas, la novela clásica de William Golding de 1954, con sus correspondientes adaptaciones cinematográficas y, más recientemente, las novelas y películas de Los juegos del hambre, así como las últimas cintas de la saga Harry Potter).

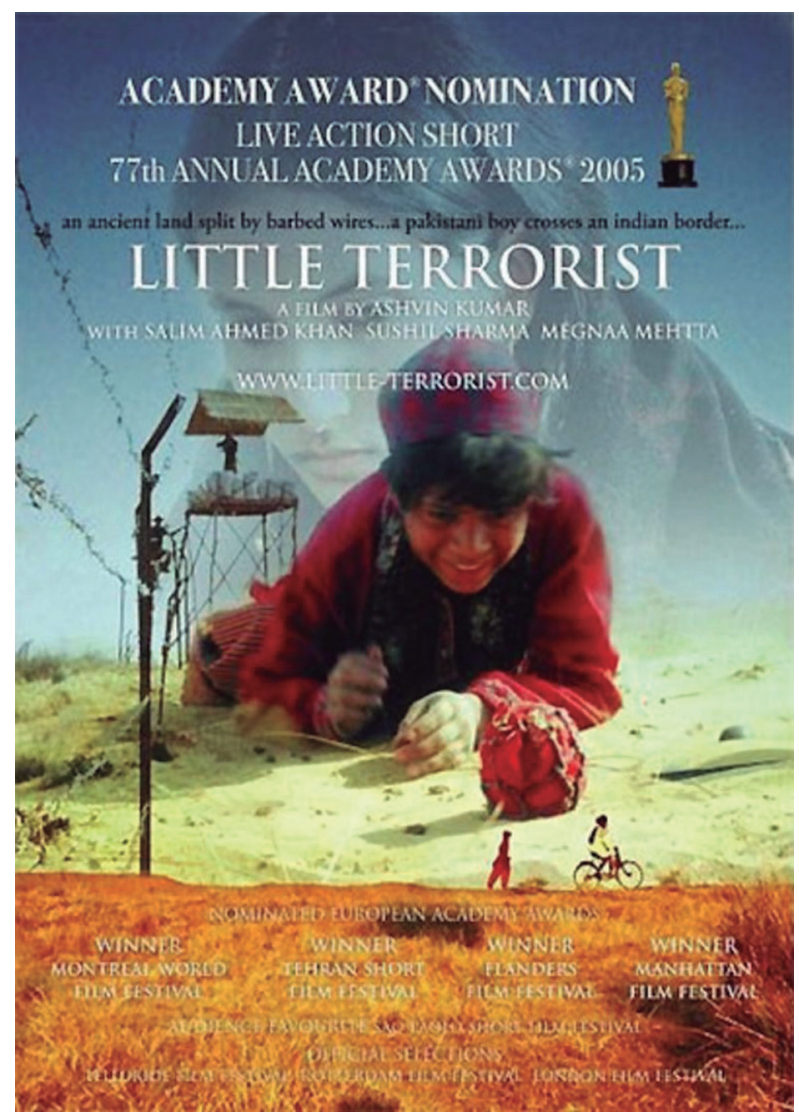

Figura 1. Ashvin Kumar, Little Terrorist 


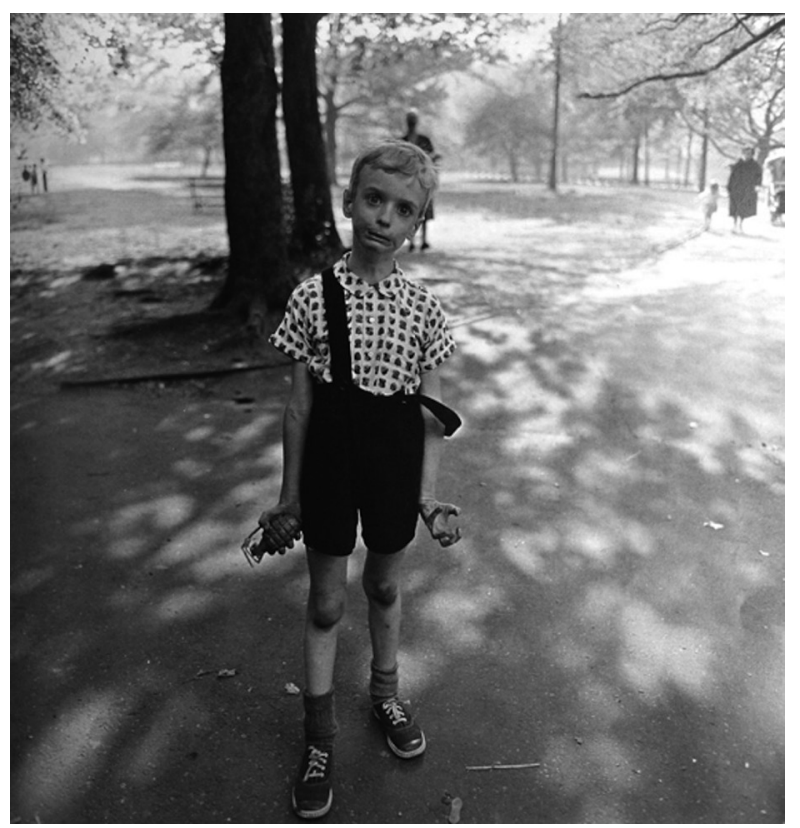

Figura 2. Diane Arbus, "Child with a Toy Hand Grenade in Central Park"

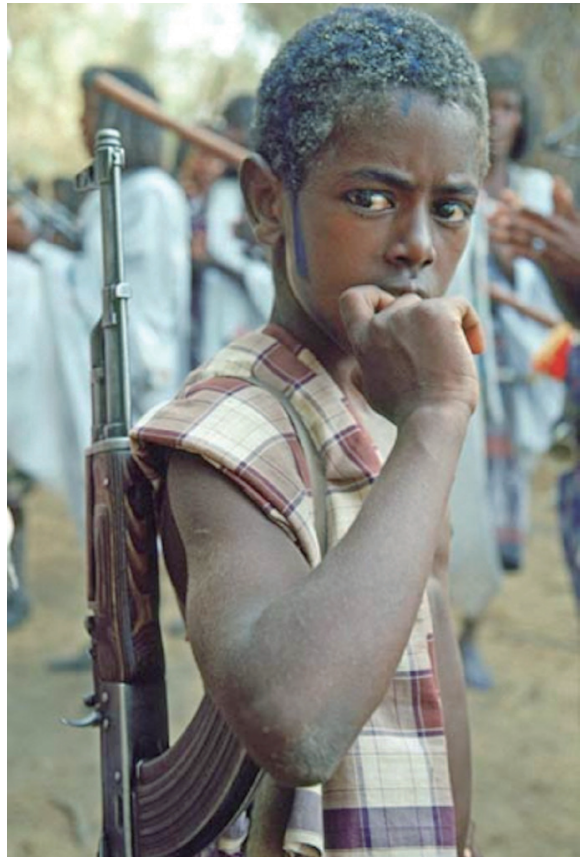

Figura 3. Child soldier in Sudan 
Estas imágenes, por supuesto, son de tres tipos distintos, y aun así resuenan entre ellas, creando una serie generalizable que bien podría multiplicarse con amplitud. Cada una de estas imágenes alude a una violencia contextual que está apenas debajo de la superficie, entendida pero no representada gráficamente excepto en la tensión de los cuerpos de los niños - una violencia anclada intensamente en la historia, y previa a la fotografía-. En Arbus, es la granada que falta en la mano izquierda del niño y el contexto histórico de la guerra de Vietnam; en la fotografía de Sudán, se trata de las guerras civiles sin fin, identificables por el pelo polvoriento del niño, por sus ojos traumatizados y el gesto de morderse las uñas, por los adultos vestidos de blanco, borrosos en el fondo; en el afiche de Kumar, se ve la historia de la separación geopolítica, simbolizada por el alambrado, la caseta del guardia, el niño andando a gatas como si fuera un soldado atravesando un campo de minas por explotar.

En cierto sentido, al considerar estos contextos violentos, para el espectador de estas fotografías, ver un arma real en las manos de los niños tiene más sentido (si se puede usar esa frase) que un juguete y, en cualquier caso, los juguetes tienden a emular armas. Es la atmósfera de violencia sofocada que rodea a estas imágenes la que da peso y construye la tensión en las caras de los niños, pero también la reacción del espectador. No obstante, las motivaciones del niño nos chocan como inaccesibles, inexplicables o, al menos, resistentes al análisis. "We should start again [dice Kathryn Bond Stockton] with the problem of the child as a general idea. The child is precisely who we are not and, in fact, never were. Is the act of the adults looking back" (5). Pero, cuando miramos hacia atrás, ¿hacia qué miramos, precisamente?

La muy reproducida fotografía de Arbus es sin duda la más discutida de estas tres imágenes inaugurales. Tomada durante los primeros años de la guerra de Vietnam, como una en una serie de fotos de niños ricos de Nueva York, Arbus famosamente acorraló al niño, tomándole foto tras foto mientras este se volvía cada vez más impaciente con ella, hasta que (como indica la hoja de contacto), el niño gradualmente dejó de sonreír y ella lo capturó haciendo un mohín. Para Judith Butler, en general, "her [Arbus] figures remain stubbornly on the surface. [...] they do show us something about the ordinary performance of obduracy" (120). Y aun así, en esta imagen particular, la inmutable expresión externa (rostro retorcido, manos tensas) indica otras tensiones internas. El sujeto de esta fotografía, Colin Wood, entrevistado más de cuarenta años después por Hugh Hart, recapitula sobre la imagen que en cierto sentido ha venido a moldear su vida pública. En un punto en la entre- 
vista, explica el fuerte contraste entre sus dos manos: la derecha sujetando la granada, la izquierda como una garra, vacía: "esa granada era una de dos que compré en una tienda de baratijas. La segunda salió por la ventana cuando traté de volar el callejón detrás de nuestro departamento". Recapitulando, Wood proyecta una mezcla incompleta de inocencia e intenciones asesinas, confirmando nuestras sospechas: los niños hacen cosas terribles, o tienen pensamientos terribles, debido a que no están atados por una moral adulta que pondría límites a su deseos violentos.

En una entrevista distinta, con David Segal, Wood añade más detalles sobre su tensión corporal, y dice: "Me pilla en un momento de exasperación. Es cierto, estaba exasperado. Mis padres se habían divorciado y había una sensación general de soledad, de haber sido abandonado. Simplemente estaba explotando. Ella vio eso [...]". Aquí, en esta reflexión del adulto sobre el niño que fue, podemos aducir la textura agregada que une al niño en Central Park, Nueva York, con el niño soldado de Sudán: la sensación de abandono que tensa el cuerpo del niño, que lo hace explotar, figurativamente, y que lo motiva a querer hacer explotar otros lugares/personas. Butler sucintamente define la fascinación continua de Arbus para nosotros, una cualidad que también discernimos en la fotografía sudanesa: ella nos hace ver "what one 'should not' enjoy seeing" (119). El niño en cada una de estas fotografías es al mismo tiempo vulnerable y peligroso; está sobre-contenido, tenso como una bomba, y listo para explotar (de nuevo). Y, de hecho, en el pasado reciente de la fotografía ya ha explotado: Colin Wood ya ha intentado hacer volar su callejón con la granada que falta, y el pathos de la fotografía sudanesa incluye la presunción de que el niño ha disparado el arma que lleva en el hombro en alguna acción militar.

De forma similar, la imagen del afiche del niño de Kumar arrastrándose a través de un campo minado en la frontera fortificada entre India y Pakistán para recuperar su pelota de cricket, hace referencia a otras imágenes de los medios, de víctimas inocentes de los campos minados desatendidos a lo largo del Oriente Medio y el sudeste asiático, explotando durante algún juego y mutilando niños. En esta ubicación particular, también condensa un comentario político sobre el carácter absurdo de los regímenes políticos que se enfrascan en ejercitar medidas de control particulares en una comunidad unida por una etnicidad común y por un amor compartido por el deporte, pero dividida por la religión y la política. Kumar basó su cinta en un caso real de un niño pakistaní de doce años que cruzó la frontera por error en el año 2003, pero él también lo ve como una historia implícitamente global que se 
extiende más allá del sureste asiático a los conflictos entre Estados Unidos y Oriente Medio: "Después del once de septiembre, la sensación es que se declara culpable a la gente ya antes de cualquier juicio", dice Kumar. "Quería reflejar la realidad del mundo después del once de septiembre como yo la entiendo y a través de la experiencia de India y Pakistán. Esto es lo que subrayo en la película" (Sengupta). En esta cinta, por lo tanto, la presencia del niño permite a Kumar juntar consideraciones de culpa e inocencia ante la ley, en una arena transnacional condicionada por las expectativas de violencia, con preguntas sobre cómo la movilidad (o falta de ella) para los ciudadanos nacionales desafía presunciones acerca de fronteras éticas y geográficas.

La película de Kumar pone en la palestra una condensación crucial de historia y sentido que quiero explorar en el resto de este estudio, en la cual la asociación del tan presente miedo del/por el niño de las primeras imágenes se somete a una presión particular en la narrativa de frontera a través de la intervención de la accidentalidad histórica. Formas ficcionales como esta, sospecho, permiten una intervención más matizada y fecunda en preguntas sobre violencia y lealtad en la construcción de ciudadanía, que a la cultura pública le resulta prácticamente imposible enfrentar - algo que H.G. Carrillo llama "art-o-fiction" [sic] -, donde "historia [sic] is transformed into history [...] into truth" (134-135). Especialmente en los márgenes de la nación, las aseveraciones acerca de valores culturales y soberanía política son sometidas a un escrutinio particular. Aún más importante, la rareza legal de la frontera resalta, de modo gráfico, la presunción de lealtad que acompaña la cualidad accidental del nacimiento, al mismo tiempo que la proximidad de la frontera debilita estas mismas construcciones.

No es de ninguna forma coincidencia, pues, que en la cinta de Kumar el niño encuentre refugio con el profesor de escuela de la villa del otro lado de la frontera, ya que es la persona más directamente involucrada, de forma cotidiana, con infundir el conjunto de valores morales-políticos y el entendimiento histórico que moldea a los niños bajo su tutela (niños a punto de explotar) y los transforma en ciudadanos productivos de la nación. La observación de Nagel, aunque aludiendo a un contexto muy diferente, resulta apropiada aquí:

The margins of nations $[\ldots]$ are all locations where rules about citizenship and proper national demeanor are tested and contested. National symbolic boundaries, like all moral boundaries, are sites for the creation and enforcement of the rules of citizenship, the surveillance, apprehension, and punishment of 
national deviants or 'traitors', and the formation of revised or new definitions of loyalty to the nation. (147)

Reveladoramente, una de las maneras en que el profesor de la película desarticula una confrontación potencial es decirles al par de soldados indios que están registrando la aldea por el presunto terrorista pakistaní, que la mayor ambición de su "sobrino" en la vida es unirse al ejército de la India y servir a su país, donde podría - presumiblemente- emplear el tipo de violencia permitida a los soldados en la región fronteriza.

Formalmente, por supuesto, el niño en la película de Kumar es solo accidentalmente pakistaní. El profesor les recuerda a los soldados que ambos lados de la frontera están habitados por el mismo tipo de gente, un lugar común dentro de las lecciones de una nación oficialmente secular, así como un importante recordatorio de una etnicidad compartida en el área de la frontera, ${ }^{2}$ y la cinta deja claro que el acto de cruzar del niño de esta frontera arbitraria (pero minada y fuertemente vigilada) también es accidental/ inocente. Y, sin embargo, esta intervención de la accidentalidad inaugura una serie de acciones intencionales (guardias que llaman y luego disparan al invasor, más tarde, amenazando a los aldeanos) que subraya la extrañeza legal de la frontera minada y amurallada: pone en peligro a las personas que formalmente se propone proteger, familias de ambos lados de la frontera. Lo accidental en este sentido no anula el contexto histórico; implícitamente, el niño tendría que ser más perspicaz, pero también tendría que poder mantener su inocencia e ignorar la evidencia de violencia en su ambiente inmediato. En este sentido, la explosión amoral/sin sentido del niño de Arbus converge con la explosividad disciplinada de fondo en la cinta de Kumar.

Cuando me enfoco en materiales más conocidos para mí - las novelas de Carrillo y Toscana - veo un arraigamiento similar en torno a la pregunta del cuidado del niño, especialmente del niño varón, en la cúspide de la inocencia y la violencia. Ambas son novelas de la frontera, y se centran en la relación entre un profesor de historia y los estudiantes a su cargo. En estos textos, la lección de historia que se debe enseñar está en entredicho con el entendimiento del profesor de un pasado conflictivo (el contenido de ambas

2 Kumar matiza este punto: la retórica oficial de la igualdad (la presunción del soldado de que el profesor pudiera ser el terrorista, el comentario del profesor de que son todos iguales) entra en conflicto con restricciones de casta que impiden al profesor y su sobrina compartir los platos con sus inesperados invitados musulmanes. 
lecciones es la agresión imperialista por parte de los Estados Unidos). Del mismo modo, en estos textos, el profesor incita a los estudiantes a emprender acciones de cualquier tipo de rebeldía y, en el caso específico de la novela de Toscana, se alude a una violencia manifiesta que transforma a niños de educación básica en minúsculos terroristas. ${ }^{3}$

Óscar Delossantos, el protagonista y narrador de la novela de Carrillo, es un profesor de historia cubano-americano en un colegio católico de hombres que será despedido al final del semestre. Durante el desarrollo de la novela, imparte a sus estudiantes una serie final de clases de historia acerca de la revolución cubana, sus raíces históricas en la historia colonial española y norteamericana, y la noción de los Estados Unidos de tener el derecho a intervenir naciones soberanas caribeñas. Esta historia es tanto marginal como central de diversas maneras. Define la percepción que tiene Óscar Delossantos de sí mismo como latino en los Estados Unidos; categoriza la identidad cultural dominante del país (no obstante, de maneras inexploradas y no reconocidas) y, al mismo tiempo, no llega a ser más que una precaria nota al pie en los libros de historia de sus estudiantes.

Óscar quiere traer este subtexto a la superficie. Hay violencia incluso en su lenguaje, que depende, sin ninguna traducción, de una extensiva alternancia de códigos entre el inglés y el español como una forma de alterar el espacio pedagógico. Volviendo al tan despreciado libro de texto, comienza su repaso revisionista de la historia, trazando, de modo satírico, los contornos de la iniciativa colonial europea: "y entonces, of course, you would all know this because you have all read pages two thirty-three through two seventyeight for today's lecture" (59). Luego desautoriza el mito patriótico de los libros oficiales de historia con cuentos de su mucho menos acreditada familia y que describen una relación muy distinta entre Cuba y su doble herencia colonial, primero bajo el yugo de España y, luego, de los Estados Unidos. Subsecuentemente, hace que sus estudiantes ejerzan violencia física sobre sus libros de clases: los instruye a hacer origami con el retrato del presidente de los Estados Unidos William McKinley, tomado del libro de historia (104-105); a sacar hojas relacionadas con la versión tendenciosa de historia de Estados Unidos en Cuba (266); a tachar y a corregir nombres de lugares (Playa Girón en vez de Bahía de Cochinos, por ejemplo) (286).

3 El profesor que insta a la rebelión es un tropo familiar; dentro de los muchos ejemplos que podría aducir, apunto uno: Abimael Guzmán, el líder del famosamente despiadado grupo insurgente peruano Sendero Luminoso, era profesor de filosofía. 
La línea de fondo es la socialización de estos chicos cubano-americanos en esta clase de la costa oeste norteamericana, y su homologación con los chicos que impulsaron la revolución cubana en la Sierra Maestra, en 1958, y que eventualmente expulsaron de la isla tanto a Fulgencio Batista como al sistema de mecenazgo de los Estados Unidos: "There are boys in the mountains, Amá says. [...] all with the same name, boys. You think, you think, you think, but it's just all the same, boys" (246). La insistencia de Carrillo en nombrar apropiadamente pueblos, cosas y eventos es muy evidente a lo largo de la novela y sin embargo este pasaje resulta extrañamente genérico, llamando la atención sobre sí mismo en la reiteración de las palabras "same" y "boys". En general, la obligación para llamar a las cosas por su nombre ("Playa Girón" y no "Bahía de Cochinos") es un tema político y existencial crucial en la novela, como Óscar explica en otro momento: "The problem inherent with saying it's un banano, señores, is that if it isn't, it isn't. And you have called something that it isn't something else, therefore renaming each of the things that they once were, and then the question still remains do either still exist" (313). Y, aun así, los niños, aquí, se desdibujan y confunden: tienen el mismo nombre, salen de las mismas montañas, una y otra vez, de modo que los pequeños actos de rebelión en una sala de clases de los Estados Unidos pueden vincularse a los estudiantes universitarios que levantaron armas contra Batista en la Cuba de los años cincuenta.

El arte de Carrillo aquí involucra el cambio de significado que se produce cuando las palabras se deshacen, no importa cuán mínimamente, de sus anclajes. En primera instancia, con la cita de su madre (quien, para añadir otra capa de complejidad, sufre de Alzheimer) acerca de los niños en las montañas todos con el mismo nombre, la palabra "niños" en aposición sugiere que el nombre de cada uno de estos niños es, precisamente, "niño", que el hecho de volverse guerrilleros en las montañas los ha despojado de sus nombres e identidades. Por lo tanto, si bien es común que combatientes de la resistencia asuman seudónimos, esta designación genérica no es distinta del proceso mediante el cual Colin Wood se convirtió para siempre en "el niño granada". El comentario que hace Óscar en relación a esta declaración toma los dos términos básicos - same, boys - y los vuelve a poner en juego, dándoles otro significado al repetirlos: "all with the same" versus "all the same". De igual forma, los "niños" del final de la frase son contextualmente distintos: estudiantes cubanos vueltos revolucionarios en el primer caso, y en el segundo, por interpelación, los niños en la clase norteamericana, cuyas identidades se infiltran hasta mezclarse en la referencia que comparten. En este proceso de nombrar, ¿sigue existiendo cualquiera de los dos grupos de niños? 
También, aquí, existe otra capa, una capa que nos recuerda la gran diferencia de inversión emocional que destinamos a los "niños" y a los "adolescentes" o a los "hombres", debido a la cual (por ejemplo) la violencia en contra de los varones/niños es reprochable pero los encuentros violentos entre adolescentes/hombres se consideran como parte de lo normativo y compresible, especialmente, dado el miedo que producen. En este aspecto, la idea de los niños en las montañas tiene un peso emocional distinto que el de hablar sobre, digamos, hombres en las montañas. Más allá de eso, la interpelación/aposición "it's just all the same, boys" es una alusión inesperada en el texto. Cuando Óscar se dirige directamente a su clase, por lo general describe a sus estudiantes como "hombres" y, aún más, como hombres cuyos múltiples nombres ayudan al profesor de historia a recordar su propia identidad y sus propias apuestas culturales y políticas: "Escuchen señores -hombres jóvenes; all of you who have sat in these seats over the past several years; mensajeros del futuro, mis iluminadores, mis casas, mis escuelas, mis corazones, mis playas, mi sentido común, mis yucas locos - I forget all the names I have had for you- Shiny Distant Shores" $(9,318)$. La secuencia de nombres recuerda al lector lo difícil que le resulta al protagonista asir significados cuando el mundo a su alrededor está cambiando, cuando las memorias emborronadas por el Alzheimer de su madre son la única ayuda que tiene Óscar para enfrentarse a la contaminación cultural de los Estados Unidos.

Uno de los primeros críticos dice que este libro "será de interés para cualquiera que haya heredado una historia y un lenguaje con los que no pueda conectar del todo pero de todas maneras quiera preservar" (cita del Miami Herald que aparece en la portada del libro). Al encuadrar la narración a través de clases de historia, Carrillo subraya las asociaciones violentas que inevitablemente acompañan los procesos oficiales del nombrar, como el de darle nombre a la nación, así como la pérdida del nombre de los niños anónimos que son arrasados por la historia.

La novela de Toscana también se centra en un profesor de historia, Ignacio Matus, cuyas clases, como las de Óscar Delossantos, conjugan pasado y presente, las mentiras de la historia oficial y el trabajo reparador del profesor que restablece los nombres correctos y los entendimientos alternativos. El costo, por supuesto, es que la memoria restablecida trae consigo violencia renovada. La novela de Toscana toma lugar en la ciudad norteña de Monterrey entre dos eventos históricos importantes: la invasión de los Estados Unidos a México en el siglo XIX, que reformó la frontera entre los dos países (y cuyos mártires icónicos son los Niños Héroes, seis cadetes que murieron defen- 
diendo el castillo de Chapultepec de Ciudad de México en la batalla contra los norteamericanos en septiembre de 1847), y las protestas estudiantiles de 1968, que fueron parte de un movimiento juvenil mucho más global contra el imperialismo occidental. Por un lado, mirando atrás al registro histórico, Matus usa como punto de entrada un viejo mapa desplegado en su escuela, en el cual México todavía se extiende más allá del río Bravo, incluyendo el 50\% del territorio perdido en la guerra estadounidense-mexicana (17). Por otra, pensando en el coraje inspiracional de los jóvenes protestando en el presente novelístico, condena la cobardía de los colegas que argüirían que "Monterrey es un lugar pacífico, de trabajo, de valores, no de ideas atolondradas; aquí no debe de ocurrir lo que está pasando en la capital con tanto estudiante que no estudia por salir a la calle a gritar consignas" (24).

Concretamente, Matus quiere llevar las ideas revolucionarias, idealizadas en las clases de historia mexicana, más allá de simplemente gritar consignas. Concibe la idea de crear un ejército de estudiantes en su clase de sexto grado, para luego llevarlos, con permiso de sus padres y en una versión poco convencional de un viaje a terreno, a invadir Texas y recobrar el territorio perdido de México. La novela explora en profundidad las razones de Matus para esta monomanía, que en esencia se pueden resumir en un literalismo excesivo que de alguna forma se las arregla para embutir a los padres analfabetos de muchos de sus estudiantes. Su argumento tiene que ver con tomarse en serio las demandas del mapa en la pared, la historia oficial que él enseña, los prescritos saludos militares a la bandera y el canto del himno nacional en las escuelas públicas.

El director de la escuela, queriendo reprimir a Matus por su insistencia en enseñar lo que finalmente se reduce a clases de historia poco ortodoxas que se toman la retórica patriótica demasiado literalmente, le dice a su colega: "la escuela es un lugar de formación, no de información" (25). Del mismo modo, su amigo Román arguye que todos serían mucho más felices y estarían mejor si esta historia de la invasión de los Estados Unidos estuviera definitivamente enterrada:

Hace ciento veintitantos años esta misma plaza se llenó de gringos uniformados y bien armados; por suerte yo no lo vi, debe de ser humillante que en tu ciudad mande un ejército invasor. Tú lo has dicho, Matus, humillante, pero fue hace tanto tiempo que ya nadie lo recuerda y pocos lo aprenden, así que olvida el asunto. (34) 
Ambos interlocutores suenan eminentemente lógicos, por supuesto, al mismo tiempo que revelan la hipocresía que yace en el centro de cualquier formación educacional patriótica que busca construir nación. Matus, por supuesto, rechaza la idea de un olvido saludable de la historia, y cree firmemente que la información precisa es crucial para la formación adecuada de una ciudadanía "iluminada", que debe subsecuentemente actuar en función de este conocimiento.

Para el director, esta posición es execrable, y arguye: "sus ideas no van con los tiempos, no es correcto despertar en los alumnos inclinaciones a la violencia", a lo que Matus responde que no se trata de una idea suya, que él simplemente está citando el himno nacional, una parte obligatoria de la educación pública en México (24-25). Tenía un punto. El himno mexicano es un ejemplo de esas típicas canciones ávidas de sangre que las naciones alrededor del mundo a menudo adoptan, y cuyas letras se vuelven tan familiares que la gente por lo general pierde la noción de la importancia que tienen como propaganda usada por el gobierno para crear una sensación del ciudadano ideal. Al incitar a sus estudiantes a unirse a su expedición militar, está de hecho escuchando atentamente, y tomándose al pie de la letra el estridente llamado a las armas de ese himno nacional: "Piensa — oh patria querida! que el cielo/ Un soldado en cada hijo te dio".

En la novela que sigue, Matus y su banda de cinco niños - el "ejército iluminado" del título - se pierden en el desierto, no llegan a estar a menos de cuarenta kilómetros de la frontera con los Estados Unidos, y se ven involucrados en un tiroteo absurdo en una granja mexicana que confunden con territorio enemigo y que finalmente recibe más daño de parte del ejército mexicano, que había sido llamado para lidiar con lo que se pensaba era una banda de terroristas locales. Fuera del tutelaje de Matus y de la perspectiva del narrador sobre estos eventos pasados, es difícil acceder a cómo estos niños de doce años imaginan el registro histórico, o a lo que piensan de la expedición. La narración en esta novela es retrospectiva, desde el punto de vista de los amigos de Matus y no de los sobrevivientes de la banda de desarrapados, y estos amigos están recapitulando un incidente de hace cuarenta años que solo recuerdan vaga e inconsistentemente, ya que supieron de él de segunda mano y no fueron testigos de los eventos que narran (y que, en cualquier caso, han sido enterrados y olvidados oficialmente).

Si otros niños mencionados en este artículo parecen a punto de explotar, y hacen que contemplarlos sea incómodo debido a esto, aquí sucede lo contrario. Distanciados por capas de olvido narrativo y oficial, lo que resulta 
más visible en la representación de los cinco niños soldados es su inocencia. Dentro de los escasos detalles que apuntan a sus motivaciones, podemos trazar una suerte de entendimiento a partir de la lista de cosas que llevan con ellos a la guerra. El rango de objetos incluye una cáscara de plátano, papel higiénico, barniz de zapatos, agujas para coser, un paquete de tachuelas y - del único niño que parecía tener claro en qué consistía la misión- un diccionario bilingüe "en el cual, para su fácil consulta [Ubaldo] subrayó palabras como rendición, fusilamiento, prisionero, tregua y amnistía" (77). La única niña del grupo lleva consigo objetos estereotípicamente femeninos: "La mochila de Azucena es rosa; muestra el dibujo de una rubia patinadora en hielo" (75), con pocas cosas adentro excepto la caja de maquillaje de su madre, ya que ha aprendido de las películas que es importante para cualquier mujer maquillarse antes de la batalla. En otras palabras, la guerra que Matus se toma tan en serio es para ellos una extensión del juego, incluso cuando - o quizás especialmente cuando - se ven involucrados en una verdadera balacera, con resultados trágicos para dos de los niños.

Toscana teje una historia en la cual la leyenda de los niños héroes se mezcla en las mentes infantiles con el sueño de la súper-heroicidad que viene de los cómics. Si los superhéroes son inmunes a las balas y, como Superman, impunemente ondean o se visten con la bandera, este no suele ser el caso en la vida real. Como atestigua el ejemplo histórico de los niños héroes, el desafío de quién portará la bandera, o se envolverá en ella para evitar que el enemigo la deshonre, es un alto honor, pero a menudo también resulta fatal (116). La inmortalidad es un concepto patriótico, no literal. Para los niños, sin embargo, la inmortalidad es algo que se da por sentado, parte del juego; incluso en la balacera absurda, muestran poco entendimiento de la muerte.

La novela de Toscana, entonces, nos hace preguntarnos acerca de la imposibilidad, en esta área fronteriza degradada, de lograr un acto significativo desde el punto de vista histórico, y, en el hilo de lo que vengo detallando, también nos hace preguntarnos acerca del rol formativo que juegan las historias oficiales que ensalzan la violencia con fines patrióticos y de crear nación. La masacre de un número todavía desconocido de estudiantes en octubre de 1968 en Tlatelolco es el telón de fondo del que no se habla, y moldea su gesto oficial final. Argüelles, el capitán de la policía, libera a Matus de la cárcel, comentando la buena suerte de su malograda aventura. Con lo que pasó en Ciudad de México, le dice, "lo menos que queremos es que el ejército siga llamando la atención. No somos perseguidores de gente con ideales, como usted y sus muchachos, solo tratamos de mantener el orden [...] Por su bien, 
olvídese de que estuvo aquí enjaulado, olvídese de que nos vio y de todo lo que hablamos, y por sobre todo olvídese de los gringos" (192). La historia es tanto lo que se nos impone olvidar como lo que se requiere que recordemos, y en cada caso, la violencia da cuerpo a los modos y justificaciones para la acción oficial.

Los proyectos de Carrillo y Toscana son quijotescos en su esencia, con el tipo de idealismo fallido que solemos asociar a semejantes producciones literarias. En ambos casos (y esto también es cierto de las escenas cortas del profesor en Little Terrorist), los lectores/espectadores nos vemos confrontados con la incoherencia de un proyecto nacional que aúna y condena la violencia como un elemento crucial de la formación normativa de los niños, especialmente los hombres. Queremos que aprendan estas lecciones y sin embargo tememos que las tomen al pie de la letra. Son niños, después de todo, todos iguales y, a todos, les hemos enseñado a jugar con armas.

\section{Obras citadas}

Arbus, Diane. "Child with Toy Hand Grenade, 1962".

Metropolitan Museum of Art. Web.

Butler,Judith. "Diane Arbus: Surface Tensions". Artforum

International 42.6 (2004): 119-124. Impreso.

Carrillo, H.G. Loosing My Espanish. New York: Random House, 2004. Impreso.

"Child Soldier in Sudan". SOS Children's Villages (NGO). Web. 14 de diciembre de 2012.

Hart, Hugh. "Post-developments/For the subject of Arbus' "Child with

a toy hand grenade', life was forever altered at the click of a shutter".

San Francisco Chronicle. Web. 19 de octubre de 2003.

Little Terrorist. Dir. Ashvin Kumar. Alipur Films, 2004. Filme.

Nagel, Joane. Race, Ethnicity, and Sexuality: Intimate Intersections,

Forbidden Frontiers. New York: Oxford UP, 2003. Impreso.

Segal, David. "Double Exposure". The Washington Post. Web. 12 de mayo de 2005.

Sengupta, Hindol. "I wanted to reflect India-Pakistan post 9/11". India Glitz. Web. 27 de enero de 2005.

Stockton, Kathryn Bond. The Queer Child, or Growing Sideways in the Twentieth Century. Durham: Duke UP, 2009. Impreso.

Toscana, David. El ejército iluminado. Barcelona: Tusquets, 2006. Impreso. 